\section{Biodiversity needs the help of global change managers, not museum-keepers}

SIR - As observed in your News Feature “Dollars and sense ${ }^{\prime \prime}$ (Nature 437, 614-616; 2005), there is increasing evidence that many conservation organizations remain focused on single species instead of addressing the urgent problems caused by loss of ecosystem functionality.

More and more conservation scientists are calling for a holistic approach that considers ecological processes and the functional properties of ecosystems, rather than just parts and patterns of species, as crucial conservation targets (see, for example, P. Kareiva and M. Marvier Am. Sci. 91, 344-351; 2003).

However, ecosystem functions - which become services when used by people are not yet considered in most mainstream conservation approaches. Another shortcoming is the rather static view of biodiversity held by many conservation organizations today. Thus, there are even more reasons for a paradigm shift in conservation than those addressed in your News Feature.

"The anthropogenic climate change that is expected during the next century looms as an overarching and unprecedented threat. " - P. Ibisch, M. Jennings, S. Kreft

Ecosystem functionality means that an ecosystem itself can sustain processes required to maintain its parts by being, for example, resilient enough to return to its previous state after environmental disturbance. Functionality depends in various specific ways on the quantity and quality of a system's biodiversity. An important characteristic of ecosystem functionality is that it develops and responds dynamically to constantly occurring environmental changes.

The anthropogenic climate change that is expected during the next century looms as an overarching and unprecedented threat to biodiversity. The predicted rate of warming alone may move many species well beyond their current climate-niche ranges.

Some species will find themselves in habitats that are unsuitable in many secondary ways, for example, as specific breeding microhabitats or for symbiotic interaction with other species.

Further, individual species within an ecosystem will be threatened by unpredictable factors, such as changes in seasonal resources and in the biogeography of pathogens, predators and competitors, which could trigger extinction events.

Although ecosystems never have been in a steady state and species distributions have always been on the move at one timescale or another, it is now more clear than ever that it is impossible to statically conserve current biodiversity patterns, in hotspots or anywhere else.

Unfortunately, many conservationists have not yet grasped the need to be 'global change managers' rather than museum-keepers, a shift of perception that is urgently required to mitigate the impacts of global change and help ecosystems adapt to them.

Pierre L. Ibisch`, Michael D. Jennings†, Stefan Kreft*

*University of Applied Sciences Eberswalde, Alfred-Möller-Str. 1, 16225 Eberswalde, Germany †The Nature Conservancy, Global Conservation Approach Team, 530 South Asbury, Moscow, Idaho 83843, USA

\section{Biodiversity: journals must take a broader view}

SIR — Biodiversity hotspots have been useful tools in prioritization, particularly in identification of critical gaps in protected areas. The analysis of avian hotspots cited in your News Feature "Dollars and sense" (Nature 437, 614-616; 2005) did not find them ineffective, but recognized that hotspots based on different taxa or indices are not necessarily congruent and a synthetic approach is required.

Although, as your News Feature suggests, more attention needs to be paid to preserving ecosystem function, we are facing a biodiversity crisis. Neither ecosystem function nor hotspots should be the sole focus of conservation efforts: we need both. Arguing the economic perspective may be a good approach to lobbying, but it is not a replacement for urgent, targeted action.

Conservation efforts also require evaluation: audits require detailed appraisal, in addition to any reporting required by donors. Large conservation organizations can fulfil these criteria relatively easily, but most conservation practitioners are small scale, depending on volunteers, drawing on very limited funds and lacking spare capacity to permit such audit. Limited audit would provide a certain amount of information, but only from the most easily reviewed and most positive cases.

For conservation efforts to be maximally useful, failures must be reported as candidly as successes.

The real gap lies not so much in analysis but in reporting: we need journal editors to take a broader view of what is of interest to a wide readership and to consider more case studies, even when these are not 'groundbreaking. Publication of results needs to be brought into the mainstream. This requires a major editorial change, allowing a shift away from the current domination of analysis and theory, to reporting of real conservation science.

Justin Gerlach

Nature Protection Trust of Seychelles, University Museum of Zoology, Downing Street, Cambridge CB2 3EJ, UK

\section{Biodiversity: saving Florida panther makes sense}

SIR - Your News Feature "Dollars and Sense" (Nature 437, 614-616; 2005) asks whether we should focus more on economic value and less on the biological needs of imperilled species. You give the Florida panther (Puma concolor coryi) as an example of endangered species recovery that may not make "economic or scientific sense". In fact, it does make sense.

The Florida panther was listed by the Endangered Species Act (ESA) in 1973, when perhaps as few as 30 individuals remained in south Florida. The population contained low genetic variation and physical abnormalities associated with inbreeding depression.

In 1995, wildlife managers embarked on a genetic restoration programme, releasing female Texas pumas into south Florida. A subsequent reduction in genetically based defects and an increase in survival and reproduction suggest that the programme was a success.

Today the population numbers nearly 90 individuals, an astonishing increase, directly attributable to ESA measures. Although significant threats remain, the panther now has a fighting chance at recovery.

The News Feature does not consider the economic value of conserving panthers. The species is a major attraction for tourists, and more than 1.3 million specialitylicence plates have been purchased by people in Florida, generating more than $\$ 30$ million for panther conservation.

Interested readers may contact the author at hartt@nwf.org for a list of publications on Florida panther conservation.

Laura Hartt

NationalWildife Federation, 1330 West Peachtree Street, Suite 475, Atlanta, Georgia 30309, USA

Contributions to Correspondence may be submitted to corres@nature.com. They should be no longer than $\mathbf{5 0 0}$ words, andideally shorter. They should be signed by no more than three authors; preferably by one. Published contributions are edited. 